www.jmscr.igmpublication.org

Impact Factor 5.244

Index Copernicus Value: 5.88

ISSN (e)-2347-176x ISSN (p) 2455-0450

crossref DOI:_http://dx.doi.org/10.18535/jmscr/v4i3.29

Journal Of Medical Science And Clinical Research

IGM Publication

An Official Publication of IGM Publication

\title{
Students' perceptions and attitudes towards Objective Structured Clinical Examination (OSCE) in the College of Medicine, KSAU-HS, King Fahad Medical City, Riyadh, Saudi Arabia
}

\author{
Authors \\ Abdalla A Saeed*, Waleed M Al Suwayh**, Amal S. Alomri** \\ *Associate Professor, Consultant, Dept. Of Community Medicine, OSCE Coordinator, Faculty of Medicine, \\ King Fahad Medical City, POBox 366325 Riyadh 11393, Saudi Arabia \\ Email: Saeed.abdalla@gmail.com,aasaeed@kfmc.med.sa00966502469819 \\ **Medical Students, College of Medicine, King Saud Bin Abdulaziz University for Health Science, \\ Riyadh, Saudi Arabia \\ Email:wal_112@hotmail.com,amalsa990@gmail.com \\ Corresponding Author
}

Abdalla A Saeed*

Email: Saeed.abdalla@gmail.com,aasaeed@kfmc.med.sa,00966502469819

\section{ABSTRACT}

Background: The Objective Structured Clinical Examination (OSCE) requires that examinees rotate through a series of seven OSCE stations and perform a variety of clinical tasks during a seven minutes period for all blocks.

Aim: This study was conducted to explore the perceptions of the students regarding OSCE Faculty of Medicine, King Saud Bin Abdulaziz University for Health Sciences (KSAU-HS) King Fahad Medical City.

Methods: In this cross-sectional study, a validated and pretested questionnaire was distributed to all 78 medical students. Questions included students' perceptions and attitudes concerning pre-exam orientation regarding OSCE, exam content, the incorporation of knowledge, skills, stress encountered, duration suitability and validity of OSCE stations

Results: The majority of all 78 students were males, enrolled in hematology block and living with their parents. More than $94 \%$ rated the OSCE as stressful but 56\% rated it as less stressful than other forms of examinations. In general the majority of the students rated favorably the OSCE as they agree that OSCE is fair, well administered, structured and sequenced, allowing students to compensate in some areas and minimized failing, that they were fully aware of the nature of the exam, that the tasks reflected those taught and they were fair and that requirements for each station were provided and that instructions and OSCE scores are standardized. Females were significantly more agreeing than males with the structure, conduction of the exam which minimized their chance of failing and provided opportunities for learning and is a true measure of the essential clinical skills

Conclusion: Students view OSCE as a fair and standardized way to assess clinical competencies and females were more satisfied than males.

Keywords: Medical students, perceptions, OSCE, Riyadh. 


\section{Introduction}

The assessment of clinical competence of medical students is fundamental to ensure that graduates are able to exercise their duties in patient care properly and safely. With the increasing trend of placing more emphasis on competency-based and problem-based instruction and assessment in medical curricula the Objective Structured Clinical Examination (OSCE) introduced by Harden et al ${ }^{1}$ is by almost all medical colleges including our college. The OSCE is objective because examiners use a standardized checklist of expected clinical behaviors for evaluating students. It is structured, or planned, so that every student sees the sameproblems and is asked to perform the same tasks. The OSCE is said to be clinical because the tasks are. Each OSCE station usually tests a different component of clinical competence, such as taking a history, conducting a physical examination, ordering diagnostic tests, making a diagnosis, planning treatment, or communicating with patients. Traditional methods of assessing clinical competence have proven to be inadequate because they lack direct observation of students. On the other hand OSCE has been proven and rated as the most reliable and valid tool for assessing clinical competency and has been increasingly used to provide formative and summative assessment in various medical disciplines worldwide, including nonclinical disciplines ${ }^{2,3}$. Despite a long tradition of research relating to OSCE, there have been relatively fewer studies about the perceptions of the students about OSCE as an assessment tool and its educational impact. No similar study was performed among medical students in King Fahad Medical City .This study is conceived to explore students' perception about the acceptability of OSCE process and to provide feedback to be used to improve the assessment technique The aim of the study is to obtain the opinion of medical students about various aspects of OSCE as students' feedback is regarded as a key indicator for successful implementation of the OSCE and also provides feedback for improvement

\section{Objectives}

To assess students' overall perception, acceptance and satisfaction with the objective structured clinical examination (OSCE), and to explore its strengths and weaknesses through feedback among Medical students in Faculty of Medicine ,KSAU-HS, King Fahad Medical City

\section{Subjects and Methods \\ Study Setting}

The Faculty of Medicine, KSAU-HS, King Fahad Medical City is adopting a hybrid curriculum offering Problem Based Learning as one of the main educational strategies along with lectures, clinical sessions and other teaching and learning strategies. The clinical Diagnostic Skills part of the curriculum is assessed by OSCE in ALL Blocks. The OSCE for all blocks consists of seven OSCE stations and each station is for durationof seven minutes. In All OSCE stations the candidates are assessed by Examiners. Almost all stations have Standardized patients. The OSCE station consists of a Title page, Candidates instructions including a brief scenario and a Specific Task to be performed by the student, Examiners instruction and Examiners Marking schedule, and SP instructions. Each station usually tests a different component of clinical competence, such as taking a history, conducting a physical examination, ordering diagnostic tests, making a diagnosis, planning treatment, or communicating with patients. The student has to attempt all stations. The OSCE carries $15 \%$ and $30 \%$ weight of the Final Block grade in Basic and Clinical phases respectively

\section{Study Design}

A quantitative, cross-sectional, analytical research design was used. 


\section{Study population}

The population consisted of all those student of batches 9, 10 and 11 enrolling in the Second Semester of the Academic Year 2014/2015. So no sampling was done as the total population was included in the study. Only males were enrolled in Batches 9 and 10 while both males and females were enrolled in batch 11 . All students have a Bachelor Degree in an Applied Health, Dental, Pharmacy or Science.

\section{Data collection tool}

OSCE evaluation questionnaire was used as an instrument for collecting the study data. It is a modified version of the tool which was used for data collection Pierre et $\mathrm{al}^{4}$. The modified tool consists of 25 items dividedinto 3 sections. First section includes 13 statements concerning different attributes of OSCE in general, rated in a four points likert scale: fully agree, agree, neutral, disagree. This section included items such as the fairness of the exam, area of knowledge covered, time of each station and the organization and administration of OSCE. The second section with 8 items addressing the nature of the OSCE exam, time allocated, instructions, tasks to be formed and sequence of OSCE stations rated in 3 points likert scale concerning level of agreement with statement: Fully agree, neutral ,fully disagree. The last section contains 4 items dealing with validity and reliability of OSCE in general rated in 3 points likert scale concerning level of agreement with statements: Fully agree, neutral, fully disagree

\section{Data management and statistical analysis}

Data was coded, cleaned, fed and analyzed using SPSS version 17...Descriptive analyses were conducted to determine the frequency distributions of the study variables. Association between groups was tested using the $\chi$.P value of less than 0.05 was selected level significance Participation was on a voluntary basis and students were assured that those who declined involvement in the survey would not be penalised. Results will be used only for the stated research objectives. Ethical approval was received from Institutional Review Board (IRB) King Fahad Medical city. Data collection was supervised by one male and one female student who are part of the research team.

\section{Results}

All 78 students completed questionnaires about the previous OSCE they attempted. Table 1 profiles the background characteristics of the subjects. The majority are males, enrolled in hematology block and living with their parents. Table 2 shows the results of the subject's agreement with different statements in evaluation of the OSCE. The gender differences presented are only for batch 11 because both males and females are enrolled. In the other batches only males are enrolled. About $85 \%$ rated the OSCE as stressful, $66 \%$ as intimidating while butabout $57 \%$ rated it as less stressful than other forms of examinations. In general the majority of the students rated favorably the OSCE as 70-84\% agree that OSCE is fair, well administered, structured and sequenced, allowing students to compensate in some areas and minimized failing. About 5-20\% rated all items poorly as they disagreed with all statements and $8-25 \%$ were neutral with no comments on the items studied. Females were significantly more agreeing than males with thestructure, conduction of the exam which minimized their chance of failing. Table 3 depicts the subject's perceptions on the quality of OSCE. About $10-27 \%$ of the students agree to a great extent that they were fully aware of the nature of the exam, that the tasks reflected those taught, that requirements for each station were provided and that instructions were clear and unambiguous. About a quarter of the students were not at all agreeing but over half were agreeing to some extents with all attributes studied. Females were significantly more agreeing than males that the exam instructions were clear and the exam provided opportunities for learning. Table 4 profiles perceptions of the students concerning validity and reliability of 
the OSCE. More than 10 to $35 \% \%$ agree to a great extent that OSCE scores are standardized, provide a true measure of the essential clinical skills. OSCEs are not affected bypersonality, gender and ethnicity with females acknowledging that significantly more than males. About $18-36 \%$ of the studentswere not in agreement at all with items related to the validity of the OSCE while about half or more of them were agreeing to some extent.

Table 1 Characteristics of the study subjects

\begin{tabular}{|l|l|l|}
\hline Characteristics & Number & Percentage \\
\hline Gender & 56 & \\
Males & 22 & 71.8 \\
Females & & 28.2 \\
\hline Age (years) & 29 & \\
$20-25$ & 21 & 37.2 \\
26 & 28 & 29.9 \\
$27+$ & & 35.9 \\
\hline Batch & 13 & \\
9 & 30 & 16.7 \\
10 & 35 & 38.5 \\
11 & & 44.9 \\
\hline Block & 13 & \\
Surgery & 36 & 16.7 \\
Hematology & 29 & 46.2 \\
Gastrointestinal & & 37.2 \\
\hline Home town & 40 & \\
Riyadh & 38 & 51.3 \\
Others & & 48.7 \\
\hline Living with & 31 & \\
Parents & 17 & 39.7 \\
Other family members & 11 & 21.8 \\
Friends & 13 & 14.1 \\
Alone & 6 & 7.7 \\
Others & & \\
\hline
\end{tabular}

Table 2 Subjects perceptions of the quality of OSCE performance in general $\mathrm{n}(\%)$

\begin{tabular}{|l|l|l|l|l|l|}
\hline Item & Fully Agree & Agree & No comment & Disagree & $\begin{array}{l}\text { P value Gender } \\
\text { difference }\end{array}$ \\
\hline Exam was fair & $21(26.9)$ & $35(44.9)$ & $13(16.7)$ & $9(11.5)$ & NS* \\
\hline Wide knowledge area covered & $17(21.8)$ & $47(60.3)$ & $9(11.5)$ & $5(6.4)$ & NS \\
\hline Needed more time at stations & $30(38.5)$ & $27(34.6)$ & $5(6.4)$ & $16(20.5)$ & NS \\
\hline Exams well administered & $19(24.4)$ & $37(47.4)$ & $14(17.9)$ & $8(10.3)$ & 0.032 \\
\hline Exams very stressful & $31(39.7)$ & $35(44.9)$ & $6(7.7)$ & $6(7.7)$ & 0.011 \\
\hline Exams well structured \& sequenced & $21(26.9)$ & $34(43.6)$ & $15(19.2)$ & $8(10.3)$ & 0.021 \\
\hline Exam minimized chance of failing & $22(28.2)$ & $33(42.3)$ & $17(21.8)$ & $6(7.7)$ & NS \\
\hline OSCE less stressful than other exams & $16(20.5)$ & $27(34.6)$ & $15(19.2)$ & $20(25.7)$ & NS \\
\hline $\begin{array}{l}\text { Allowed student to compensate in } \\
\text { some areas }\end{array}$ & $24(30.8)$ & $32(41.0)$ & $18(23.1)$ & $4(5.1)$ & NS \\
\hline Highlighted areas of weakness & $18(23.1)$ & $33(42.3)$ & $19(24.3)$ & $8(10.3)$ & NS \\
\hline Exam intimidating & $17(21.8)$ & $34(43.6)$ & $19(24.4)$ & $8(10.3)$ & NS \\
\hline $\begin{array}{l}\text { Student aware of level of } \\
\text { information needed }\end{array}$ & $11(14.1)$ & $32(41.5)$ & $19(24.4)$ & $16(20.5)$ & 0.047 \\
\hline Wide range of clinical skills covered & $16(20.5)$ & $40(51.3)$ & $12(15.4)$ & $10(12.8)$ & NS \\
\hline
\end{tabular}

NS* $=$ Not significant 
Table 3 Subjects evaluation of lastOSCE attempted n (\%)

\begin{tabular}{|l|l|l|l|l|}
\hline Item & Not at all & $\begin{array}{l}\text { To some } \\
\text { extent }\end{array}$ & To great extent & $\begin{array}{l}\text { value Gender } \\
\text { difference }\end{array}$ \\
\hline Fully aware of nature of exam & $15(19.2)$ & $55(70.5)$ & $8(10.3)$ & NS* \\
\hline Tasks reflected those taught & $16(20.5)$ & $52(66.7)$ & $10(12.8))$ & $\mathrm{NS}$ \\
\hline Time at each station was adequate & $19(24.7)$ & $40(50.6)$ & $19(24.7)$ & $\mathrm{NS}$ \\
\hline $\begin{array}{l}\text { Requirements for each station are } \\
\text { provided }\end{array}$ & $18(23.1)$ & $39(50.0)$ & $21(26.9)$ & $\mathrm{NS}$ \\
\hline Instructions were clear and unambiguous & $22(28.2)$ & $37(47.4)$ & $19(24.4)$ & 0.005 \\
\hline Tasks asked to perform were fair & $14(17.9)$ & $51(65.4)$ & $13(16.7)$ & $\mathrm{NS}$ \\
\hline Sequence of stations appropriate & $13(16.7)$ & $46(58.9)$ & $19(24.4)$ & $\mathrm{NS}$ \\
\hline Exam provided opportunities to learn & $16(20.5)$ & $44(56.4)$ & $18(23.1))$ & 0.036 \\
\hline
\end{tabular}

NS* = Not significant

Table 4 Students perception of Validity of OSCE

\begin{tabular}{|l|l|l|l|l|}
\hline Item & Not at all & $\begin{array}{l}\text { To some } \\
\text { extent }\end{array}$ & To great extent & $\begin{array}{l}\text { P value Gender } \\
\text { difference }\end{array}$ \\
\hline $\begin{array}{l}\text { OSCE exam scores provide true } \\
\text { measure of essential clinical } \\
\text { skills }\end{array}$ & $22(28.2)$ & $40(51.3)$ & $16(20.5)$ & NS* \\
\hline OSCE scores are standardized & $20(35.6)$ & $50(64.1)$ & $8(10.3)$ & NS \\
\hline OSCE is a useful experience & $14(17.9)$ & $37(47.4)$ & $27(34.6)$ & NS \\
\hline $\begin{array}{l}\text { Personality, ethnicity and gender will not affect } \\
\text { OSCE scores }\end{array}$ & $22(28.2)$ & $44(56.4)$ & $12(15.4)$ & 0.030 \\
\hline
\end{tabular}

NS* = Not significant

\section{Discussion}

OSCE has become the gold standard tool for evaluating the clinical competency of medical and other health professionals in many institutions worldwide. Overall this study found that students generally perceive OSCE as a positive experience in agreement with manynational and international studies ${ }^{5-12}$. This was demonstrated by the positive responses regarding standardization, fairness, practicality and usefulness of the exam.In this study although more than $90 \%$ of the students found OSCE stressful and $66 \%$ found it intimidating but more than half of the students think it is less stressful than other forms of examinations. This is in agreement with local and international studies reporting levels of stress ranging from half to $95 \%$ ${ }^{5-13}$. Studies found that although stressful, OSCE was highly acceptable to students, was better received than many other examination types, tested clinical skills, and allowed students to identify weaknesses ${ }^{11,12}$ .Inadequate prior guidelines, inadequate time for stations, newness of the assessment format and vague instructions were the main causes for stress in some studies ${ }^{6}$. Adequate preparation of OSCE by students was found to be a method to overcome anxiety and fear of examination ${ }^{13}$. Students in this study tend to think that OSCE evaluates a wide variety of clinical skills and they perceived exam scores to be truly reflective of competence in clinical skills in agreements with comparative studies in other communities. ${ }^{9,10,11}$ Only a quarter of students in this study think that time allotted for stations is not at all adequate which is a favorable finding compared to studies reporting that $46-80 \%$ of students felt that the allocated time per station was inadequate in other studies ${ }^{11,12 ., 14}$ Other studies ,however, found that $70-100 \%$ of students felt that the time allocated to each station was adequate ${ }^{5,15}$.Differences may be due to the differences in type of OSCE, block, students levels and the differences to the times allocated for the OSCE stations. More than half of the students in this study were neutral concerning the effect personality, ethnicity, and gender on OSCE scores while only about $15 \%$ think that they affect OSCE scoring to a great extent. In a study in Malaysia about half of the students raised concerns that personality, ethnicity, and/or genderwere potential 
sources of bias that could affect their scores ${ }^{13}$. Females showed more favorable rating of the OSCE compared to males in this study. Females tend to be more accommodative in the conservative community of KSA. The participants' demographics such as sex , age and marital status had no effect on their level of satisfaction with OSCE in agreement with findings in other countries ${ }^{8}$ As can be seen from in this study the perceptions and satisfaction of medical students with OSCE have been generally positive in agreement with most national and international studies ${ }^{5-15}$. This is also true for other health professions such as dental, pharmacy and nursing students ${ }^{16,17,18}$

\section{Conclusion}

In spite of being stressful, OSCE is considered as fair and better method of examination by students as it covers wide range of skills and improves the clinical knowledge. This wide acceptance of OSCE by students could increase the satisfaction of all stakeholders involved in medical students' assessment.

\section{Recommendations}

OSCE is an effective and valid assessment method for assessing students`clinical competencies and it should be used

Effective preparation and proper orientation of students with OSCE to reduce stress, anxiety and improve their experience.

\section{Competing interests}

The authors declare that they have no competing interests.

\section{Conflicts of interest:}

The authors declare that there are no conflicts of interest

\section{Acknowledgements:}

We thank all students who participated in this survey.

\section{Authors' contributions}

AS conceptualized the study; developed the proposal, Co-ordinated the conduct of the project, supervised and completed initial Data entry and analysis, and wrote the report.

WA participated in the design of the study, coordinated the conduct of the project, supervised data collection, and assisted in writing the report.

AA participated in the design of the study, coordinated the conduct of the project, supervised data collection, and assisted in writing the report.

All authors read and approved the final manuscript.

\section{References}

1. Harden RM, Stevenson M, Downy WW, and Wilson GM. Assessment of clinical competence using objective structured examination. Br. Med. J. 1975; 1(5955): 447-51.

2. Carracci C, Englander R: The objective structured clinical examination, a step in the direction of competency-based evaluation. Arch PodiatryAdolescent Med 2000, 154:736-741. PubMed Abstract | Publisher Full TextRussell B Pierre ${ }^{1 * \dagger}$, Andrea Wierenga ${ }^{2 \dagger}$, Michelle Barton ${ }^{1}$, J Michael Branday ${ }^{2}$ and Celia DC Christie ${ }^{1}$ BMC Medical Education 2004, 4:22 doi:10.1186/1472-6920-4-22

3. Patricio MF, Julia M, Fareleira F, Carneiro AV. Is the OSCE a feasible tool to assess competencies in undergraduate

4. Pierre RB, Wierenga A, Barton M, Branday JM, Christie CD. Student evaluation of an OSCE in paediatrics at the University of the West Indies, Jamaica. BMC Medical Education. 2004; 4:22. doi: 10.1186/1472-6920-4-22. 


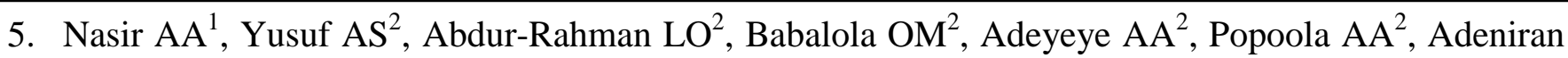
JO Medical students' perception of objective structured clinical examination: a feedback for process improvement J Surg Educ. 2014 Sep-Oct;71(5):701-6. doi: 10.1016/j.jsurg.2014.02.010.

6. Siddiqui FG . Final year MBBS students' perception for observed structured clinical examination. J Coll Physicians Surg Pak. 2013 Jan; 23(1):20-4. doi: 01.2013/JCPSP.2024.

7. Pierre RB ${ }^{1}$, Wierenga A, Barton M, Branday JM, Christie CD Student evaluation of an OSCE in paediatrics at the University of the West Indies, Jamaica. BMC Med Educ. 2004 Oct 16; 4:22.

8. Khorashad A, Salari S, Baharvahdat H, Hejazi S, Lari S, Salari M, Mazloom M, Lari S.. The Assessment of Undergraduate Medical Students' Satisfaction Levels with the Objective Structured Clinical Examination. Iran Red Crescent Med J. 2014 August; 16(8): e13088

9. Raheel $\mathrm{H}^{1}$, Naeem $\mathrm{N}^{2}$. Experience with the objective structured examination as a tool for students' assessment in the Department of Community Medicine and Primary Health Care in a university[corrected] in Western Saudi Arabia. Saudi Med J. 2002 Feb;23(2):151-5 use of objective structured

10. Shawky S. Experience with the objective structured examination as a tool for students' assessment in the Department of Community Medicine and Primary Care in a university in Western Saudi Arabia. Saudi Med J 2002; 23(2): 151-155.

11. Jabeen N, Ehsan H , Mahmood M. Students' Perception Regarding Objective Structured Clinical Examination (OSCE) Journal of Islamabad Medical \& Dental College (JIMDC); 2015:4(2):85-87

12. Elfaki O , Al-Humayed S.Medical Students' Perception of OSCE at the Department of Internal Medicine, College of Medicine, King Khalid University, Abha, KSA.Journal of the College of Physicians and Surgeons Pakistan 2016, Vol. 26 (2): 158-159

13. Fidment $\mathrm{S}$. The objective structured clinical exam (OSCE): A qualitative study exploring the healthcare students' experience. Students Engagement and Experience J 2012; 1(1) available online http://dx.doi.org/10.7190/seej.vlil.37

14. Beckett N, Hellenberg D, Namane M. A qualitative evaluation of University of Cape Town medical students' feedback of the Objective Structured Clinical Examination Mefanet J 2014; 2(1): 20-25

15. Khairy GA. Feasibility and acceptability of Objective Structured Clinical Examination (OSCE) for a large number of candidates: experience at a university hospital. J Family Community Med. 2004; 11(2):75-78.[PMC free article] [PubMed]

16. Awaisu A, Mohamed MH, Al-Efan QA. Perception of pharmacy students in Malaysia on the use of objective structured clinical examinations to evaluate competence. Am J Pharm Educ. 2007 Dec 15;71(6):118

17. Hammad $\mathrm{M}^{1}$, Oweis $\mathrm{Y}$, Taha S, Hattar S, Madarati A, Kadim F Students' opinions and attitudes after performing a dental OSCE for the first time: a Jordanian experience. J Dent Educ. 2013 Jan; 77(1):99-104.

18. Abeer Eswi, Amany S. Badawy, Halalia Shaliabe. OSCE in Maternity and Community Health Nursing: Saudi Nursing Student's Perspective. American Journal of Research Communication, 2013, 1(3): 143-162\} www.usa-journals.com, ISSN: 2325-4076 